\title{
GREEN BUILDING MATERIALS BASED ON WASTE FILLER AND BINDER
}

\author{
Nadezda STEVULOVA ${ }^{1,{ }^{*}}$, Jozef JUNAK ${ }^{1}$ \\ ${ }^{1}$ Faculty of Civil Engineering, Technical University of Kosice, Vysokoskolska 4, 04200 Kosice, \\ Slovakia. \\ corresponding author: nadezda.stevulova@tuke.sk
}

\section{Abstract}

This study is aimed at the application of alternative binder $(A B)$ into bio-aggregate-based composite. The technically important parameters (density, thermal conductivity, water absorption and compressive strength) of 28,60 and 90 days hardened green composites containing chemically and physico-chemically modified hemp hurds $(\mathrm{HH})$ with $\mathrm{AB}$ compared to the Portland cement $(\mathrm{PC})$ are presented. Testing of two reference bio-composites with original $\mathrm{HH}$ confirmed higher values of compressive strength and thermal conductivity unlike water absorption for all hardened specimens based on alternative binder (MgO-cement) compared to conventional PC. Changes in the final properties of hardened bio-composites were affected by treatment process of organic filler and alkaline nature of $\mathrm{MgO}$-cement. The combination of purified $\mathrm{HH}$ by ultrasound treatment and $A B$ appears to be promising for preparation of bio-based composite material with better properties compared to PC. In this paper, other option of the preparation of bio-composite system based on original (non-treated) filler and binder consisting of optimal activated $\mathrm{MgO}$ and silica fume is presented.
\end{abstract}

Keywords:

Green composite;

Bio-aggregate;

Hemp hurds;

MgO-cement;

Silica fume.

\section{Introduction}

Bio-composites based on lignocellulose aggregates with inorganic matrix belong to popular building products due to the advantageous and useful physical and chemical properties of their biopolymer constituents. These lignocellulose materials obtained from plant raw materials attract an incredible level of attention to use them in the production of environmentally friendly materials with high utility value from the point of view of construction sustainability. Their porous structure motivated eco-builders for the exploitation of natural lignocellulose sources and recyclable bio-waste as filler constituents into green composites, and in the design and development of new bio-based materials with fascinating ability to regulate the indoor moisture level and to ensure better indoor air quality [1]. Bio-aggregate-based composite are also providing good insulation properties [2]. There is a large group of fast renewable vegetal-origin materials, of which great importance to technical hemp is attached. Hemp hurds $(\mathrm{HH})$ as waste product coming from fibre production usually ending up in landfills [3] is utilised mainly for production of bio-based composites [4].

However, high moisture sorption sensitivity of lignocellulose bio-aggregates causes the chemical degradation of their structure, dimensional variation, and their heterogeneity leads to a weak adhesion at biomass particles-matrix interface [5]. As known [6], the bio-aggregates withdrawing the water molecules from the surrounding cement paste, and occurring the solution of extractive sugar components from the $\mathrm{HH}$ and their interaction with $\mathrm{Ca}^{2+}$ ions from the cement inhibit the cement hydration process. Alkaline environment of concrete causes the degradation of lignocellulosic structure by its weakening. Aiming to enhance lignocellulosic bio-aggregates behaviour with cement based matrices, the many procedures of chemical and physical treatment, also combination of ways for fibrous particles [7] have been studied. The important contribution of cement production to $\mathrm{CO}_{2}$ emissions is driving force behind the search for alternative binders with lower carbon oxide footprint [8]. Matrix modification by adding pozzolanic by-products to Portland cement represents one of ways 
of more sustainable binders [6, 8]. The study of lime-based composites with $\mathrm{HH}$ (hemp concrete or hempcrete) showed [1,9] low compressive strength values (less than $2 \mathrm{MPa}$ ), therefore these products are non-load-bearing but with overall thermal conductivity of about $0.1 \mathrm{~W} / \mathrm{mK}$ [10]. While the incorporation of $\mathrm{HH}$ in the cement or lime matrix is known, its integration in alternative binder matrix based on MgO-cement has not yet been systematically studied. A lower calcination temperature of magnesite $\mathrm{MgCO}_{3}$ to magnesia $\mathrm{MgO}$ compared to the conversion of calcite $\mathrm{CaCO}_{3}$ leads to potential energy savings [11]. The production of $\mathrm{MgO}$-based cements is based on the combination of $\mathrm{MgO}$ with phosphates or magnesium chlorides. In the last years, an attention has been devoted to blend of $\mathrm{MgO}$ and silica fume as binder for magnesium silicate hydrate (M-S-H) cements [12]. In our works [13-15], it has been showed that the MgO-cement system based on optimally milled $\mathrm{MgO}$ in the mixture with silica sand and alkaline substance addition is suitable for application into bio-aggregate-based composites. As shown, modification of surface properties of bio-aggregate material and binder nature play a major role in the evolution of macro- and microscopic properties, essentially strength parameter of such bio-aggregate-based composites.

Our research direction was motivated by very limiting knowledge of the alkaline binder's influence on the lignocellulose bio-aggregates. Also behaviour of bio-aggregates pre-treated by different procedures in the alkaline environment of matrix is not sufficiently explained. Therefore, the main objective is to understand the mechanism of interactions between lignocellulosic bio-aggregates and particles of $\mathrm{MgO}$-cement in relation to the physical and mechanical properties of hemp hurds composites.

\section{Experimental}

\subsection{Materials}

\subsubsection{Binders}

Portland cement CEM I $42.5 \mathrm{R}$ (Holcim, Turna nad Bodvou) and MgO-cement as conventional and alternative binders were used for preparation of the mixtures. MgO-cement $(A B)$ consisted of dry milled magnesium oxide (commercial product CCM 85 taken from Slovak Magnesite Factory in Jelsava, Slovakia; MgO prepared under optimal calcination temperature in laboratory), silica (sand from Sastin, Slovakia; silica fume), and alkaline activator (sodium hydrogen carbonate p.a.).

\subsubsection{Bio-aggregate}

Hemp hurds (Hempflax, Netherland) with polydispersive particle size distribution was used as a filler material into bio-composites. Detail properties characterization is given in [16, 17].

\subsection{Methods}

\subsubsection{Pre-treatment processes of hemp hurds}

Two treatment procedures of dried hemp hurds were used. Chemical modification of organic material was made by using of sodium hydroxide solution $(\mathrm{ATHH})$, and calcium hydroxide (CTHH) under conditions described in the paper [18]. A combination of physical and chemical treatment of $\mathrm{HH}$ particles took place in an ultrasonic cleaner bath (TESON 10, $220 \mathrm{~V}, 50 \mathrm{~Hz}, 650 \mathrm{~W}$ ). As a cleaning medium was used deionized water (UWTHH) and $0.2 \mathrm{M} \mathrm{NaOH}$ solution (UATHH) where the ratio s:I (solid to liquid phase) was 1:10.

\subsubsection{Preparation of bio-aggregate-based composites}

Experimental mixtures consisting of $\mathrm{HH}$ (original and treated) and binders were prepared according to the recipe ( $40 \mathrm{vol}$. \% of hemp hurds, 29 vol.\% of binder and 31 vol. \% of water). Labeling of individual recipes is given in Table 1. After dry homogenization of the components, mixing with water addition followed. The cube specimens of hemp composites $100 \times 100 \times 100 \mathrm{~mm}$ were cured for $48 \mathrm{~h}$ in an indoor climate. After remolding, the bodies were covered with a foil and subsequent hardening took place under laboratory conditions during for 28, 60 and 90 days. For comparative study, referential composites based on original hemp hurds with Portland cement $(\mathrm{PCHH})$ and $\mathrm{MgO}$ cement $(\mathrm{RHH})$ were made. 
Table 1: Recipes of mixtures.

\begin{tabular}{|c|c|}
\hline Recipe & Mixture components \\
\hline $\mathrm{R} 1$ & $\mathrm{PC}$, water \\
\hline $\mathrm{R} 2$ & $\mathrm{CCM}^{2}$, silica sand, $\mathrm{NaHCO}_{3}$, water \\
\hline $\mathrm{R} 3$ & $\mathrm{MgO}$, silica sand, $\mathrm{NaHCO}_{3}$, water \\
\hline $\mathrm{R} 4$ & $\mathrm{CCM} 85$, silica sand, water \\
\hline $\mathrm{R} 5$ & $\mathrm{MgO}$, silica sand, water \\
\hline $\mathrm{R} 6$ & $\mathrm{MgO}$, silica fume, water \\
\hline
\end{tabular}

\subsubsection{Bio-composite properties determination}

The physical properties (bulk density, thermal conductivity coefficient, short-term water absorption) of hardened composites were determined in accordance with standards [19, 20]. The measurement of thermal conductivity was performed on the commercial device ISOMET 104 (Applied Precision Ltd., Germany). Compressive strength of the all hardened specimens was determined by using the instrument ADR ELE 2000 (International Limited, United Kingdom) in accordance with the standard [21].

The average values of each parameter were determined from three measurements. The variation in measurements errors represented by the standard deviation was less than $10 \%$.

\section{Results and discussion}

The bulk density values of bio-composites with treated and untreated $\mathrm{HH}$ did not change significantly with increasing hardening time 960 to $1280 \mathrm{~kg} / \mathrm{m}^{3}$. Based on the density values found, this material belongs to lightweight composites.

The development of thermal conductivity coefficient, short-term water absorption and compressive strength of bio-aggregate composites with $P C$ and $A B$ matrix in dependence on hardening time is shown in Figs. 1 - 3. As it is evident from these figures, the treatment procedure of $\mathrm{HH}$, binder nature, and hardening time affected the values of these three parameters. The values of thermal conductivity coefficient (Fig. 1) decrease with increasing hardening time, primarily the more significant decrease in conductivity is recorded for reference composite PCHH. However, the composites based on $\mathrm{MgO}$-cement show the lowest thermal conductivity coefficient values. It is evident that physical treatment of hemp hurds in alkaline solution (UATHH) has the most favorable effect on this parameter of bio-composite in comparison to other composite samples based on MgOcement. The range of measured values for hardened bio-aggregate-based composites with MgOcement matrix is acceptable in terms of the thermal insulating properties $0.17-0.06 \mathrm{~W} / \mathrm{mK}$.

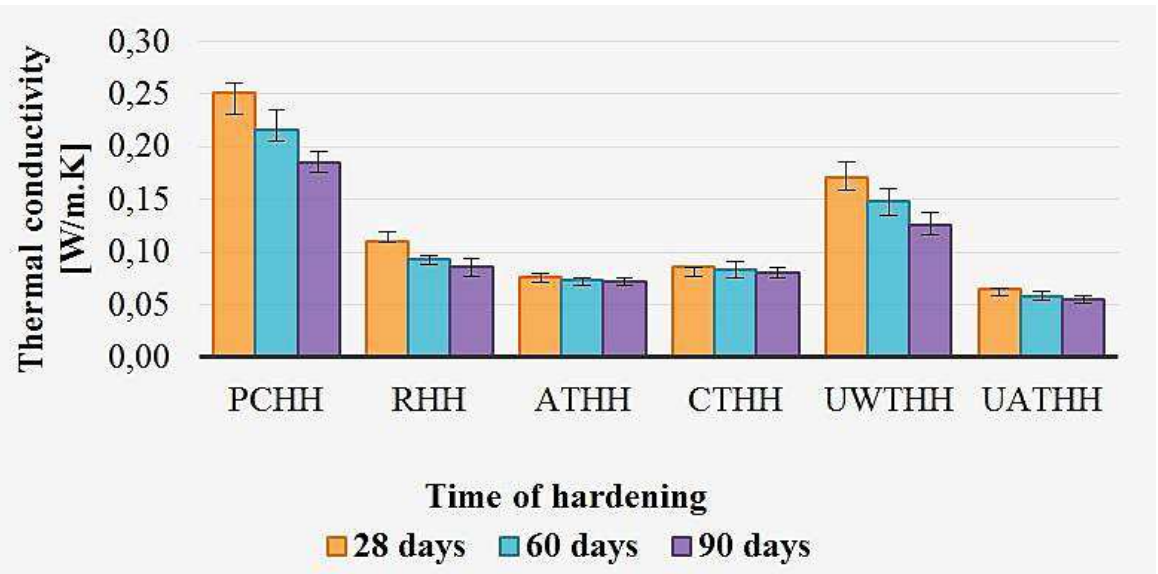

Fig. 1: Thermal conductivity coefficient values of 28,60 and 90 days hardened composites with original and treated $\mathrm{HH}$. 


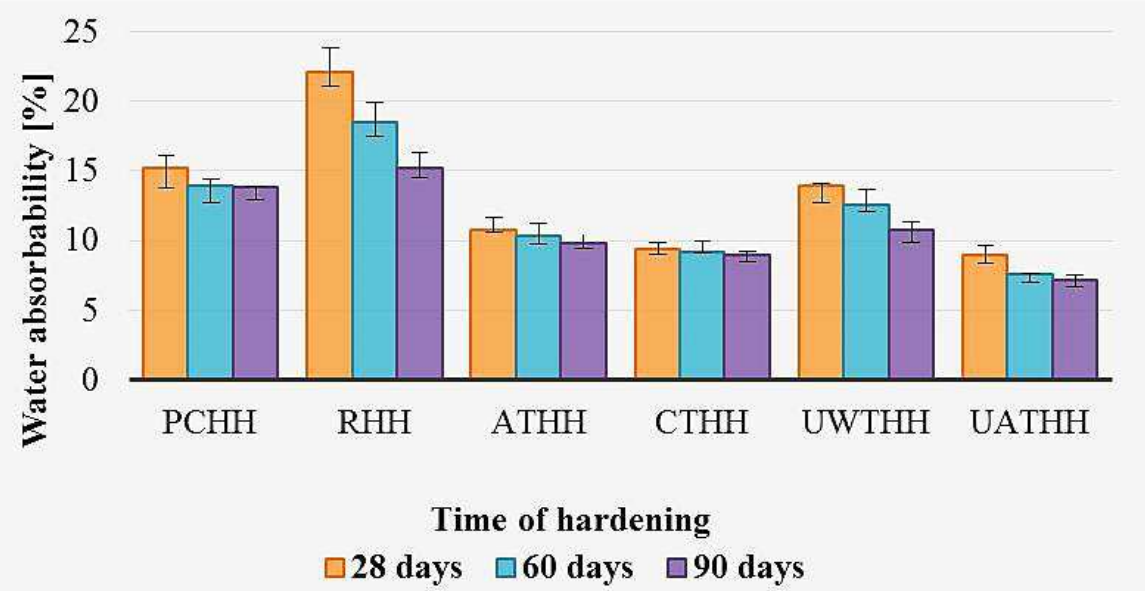

Fig. 2: Water absorption values of bio-composites with original and treated $\mathrm{HH}$ after 28,60 and 90 days of hardening.

As it is shown in Fig. 2, water absorption values of $\mathrm{PCHH}$ composites are lower when compared to $\mathrm{RHH}$. Prolonging setting time affected slightly the short-term water absorption (after 1 hour) of composite samples with modified HH (ATHH, CTHH and UATHH) unlike the reference composite $\mathrm{RHH}$. It is worth to notice the treatment processes of hemp hurds led to a reduction in water absorption by the bio-based composites. The lowest water absorption behaviour was found for UATHH composite after 90 days $7 \%$.

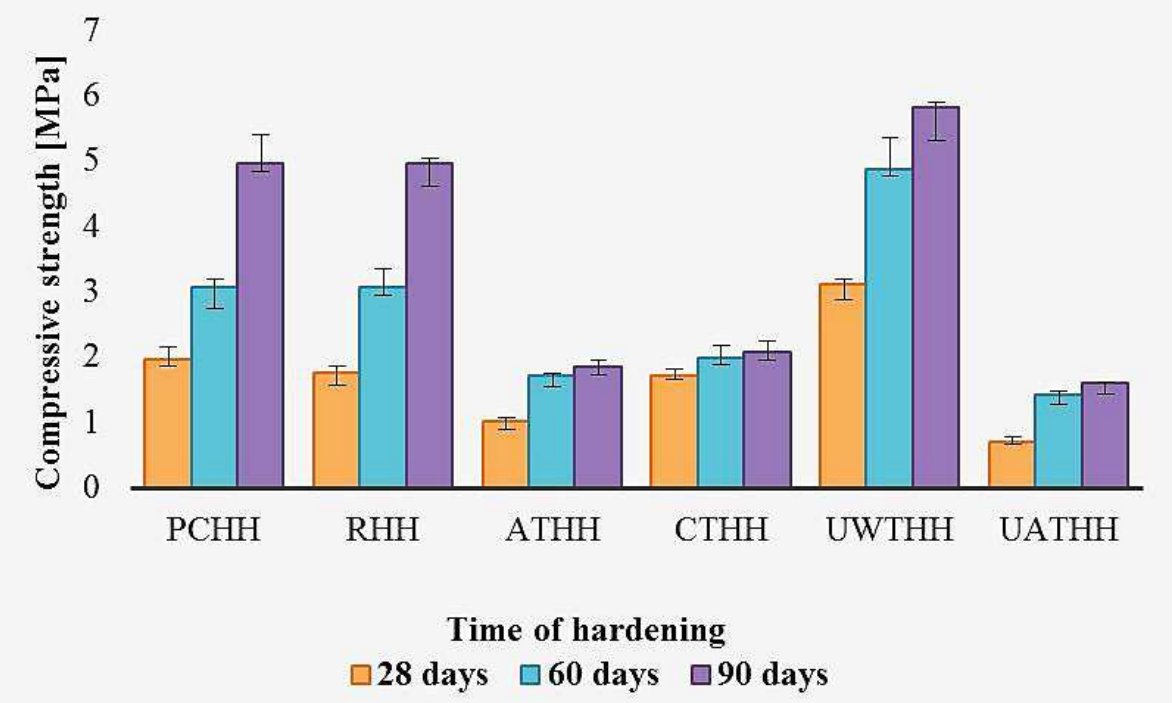

Fig. 3: Changes in compressive strength of bio-composites with original and treated $\mathrm{HH}$, Portland cement and $\mathrm{MgO}$-cement with increasing hardening time.

The compressive strength of all bio-composites increases with hardening time, Fig. 3. The composite specimen containing the $\mathrm{HH}$ modified by ultrasound treatment in water (UWTHH) achieved the highest value of strength parameter. Ultrasound process mechanism is associated with the development of local high temperature and pressure in volume of water. These conditions cause gradual breakage of the complex bundle structure of fibres and fibrils in $\mathrm{HH}$ particles. It results in the generation of more fragmented surfaces and sites on the surface of particles capable of binding, and thus better compatibility between $\mathrm{HH}$ aggregates and $\mathrm{AB}$ particles in composite system [22]. One of the causes of such behavior could be lower degree of cellulose polymerization after ultrasound treatment of $\mathrm{HH}(910)$ in comparison to original sample (1302) [17]. The specimens with incorporated hemp hurds after chemical treatment $(\mathrm{ATHH}, \mathrm{CTHH})$ and combined modification (UWTHH, UATHH) achieved lower values of strength parameter for each hardening time when compared to reference bio-composite with $\mathrm{MgO}$-cement $(\mathrm{RHH})$ and Portland cement $(\mathrm{PCHH})$. However, the differences observed in strength values found for bio-composites with treated $\mathrm{HH}$ were not significant. The low 
strength of bio-composites containing the pre-treated $\mathrm{HH}$ is related to poor adhesion of the surface of $\mathrm{HH}$ to the binder particles, caused by deteriorating quality of surface of bio-aggregates due to pretreatment process and alkaline nature of used MgO-cement, $\mathrm{pH}=12.6$. The degradation of amorphous compounds in lignocellulosic material (hemicellulose and lignin) in the pre-treatment process was not sufficient, therefore their dissolution continued in the alkaline environment of $A B$ and the released products could inhibit the processes of setting and hardening [23]. An increased surface alkalinity of the main constituent of $\mathrm{HH}$ (cellulose) caused by the formation of alkaline cellulose by reaction of $\mathrm{Na}+$ ions with the $-\mathrm{OH}$ groups present in the cellulose could also contribute to the deterioration in its adhesive behavior at the interface with $A B$ particles. This interfacial adhesion of bioaggregates and matrix particles could be probably influenced by the number of short ranged hydrogen bonding. Another reason is related to low degree of $\mathrm{MgO}$ hydration and low level of magnesium silicate hydrates formation due to a high $\mathrm{pH}$ value of $\mathrm{MgO}$-cement caused by the addition of $\mathrm{NaHCO}_{3}$ [24]. As known, the $\mathrm{pH}$ value of system brucite / water in equilibrium state calculated from the product solubility of $\mathrm{Mg}(\mathrm{OH})_{2}$ is around $\mathrm{pH} 10.5$ [25]. The presence of $\mathrm{CaO}(5.3 \mathrm{hm} \%)$ in the used $\mathrm{MgO}$ product can also potentially contribute to the increase in the $\mathrm{pH}$ value until 12.5 in the MgO-cement system. Also low reactivity of the starting, commercial raw materials of $\mathrm{SiO}_{2}$ and $\mathrm{MgO}$ plays a key role in the formation of M-S-H phase. These assumptions of $\mathrm{MgO}^{-} \mathrm{SiO}_{2}-\mathrm{H}_{2} \mathrm{O}$ system behavior can be also related to its formulation. Therefore, our effort was to modify the recipe (no alkaline admixture) by replacing the $A B$ components with more reactive materials (such as $\mathrm{MgO}$ calcined at optimal temperature under laboratory conditions and silica fume). Original hemp hurds was used in these mixtures (recipes R4-R6). As is can be seen in Table 2, the best results of measured parameters of bio-composites are obtained with specimen prepared according to the recipe $\mathrm{R} 6$ comprising reactive components ( $\mathrm{MgO}$ calcined at temperature of $700{ }^{\circ} \mathrm{C}$, specific surface area of $67.8 \mathrm{~m}^{2} / \mathrm{g}$; silica fume, specific surface area of $22 \mathrm{~m}^{2} / \mathrm{g}$ ). Compared to a bio-composite sample with the same composition, but with silica sand as a source of silicon component R5, a decrease in the density, thermal conductivity was observed about $20 \%$ and $9 \%$, respectively. The difference in water absorption values was not significant. However, the bio-composite R6 achieved a higher strength of $22.5 \%$ compared to specimen based on silica sand (R5 due to the higher reactivity of the silica particles and better contact of the silica fume particles and bio-aggregates. The small particle size of silica fume allows them to be located in smaller defects in the hemp hurds structure and to give the more compact structure in composite system. Similar interpretation was found in paper [26], where the sisal fibers were immersed in a suspension of silica fume.

Our study highlighted potential of hemp hurds utilization for preparation of bio-composites but it needs next investigation in terms of the development of long-term strength in relation to control of the formation of the M-S-H nanostructure. Also testing the durability of these bio-aggregate-based composites could confirm their use into loading construction.

Table 2: Properties of hemp hurds composites after 28 days of hardening ( $\rho$ - bulk density; $\lambda$ - thermal conductivity coefficient; WA - water absorption; CS - compressive strength).

\begin{tabular}{|c|c|c|c|c|}
\hline Recipe & $\begin{array}{c}\rho \\
{\left[\mathbf{k g} / \mathbf{m}^{3}\right]}\end{array}$ & $\begin{array}{c}\boldsymbol{\lambda} \\
{[\mathbf{W} / \mathbf{m K}]}\end{array}$ & $\begin{array}{c}\text { WA } \\
{[\%]}\end{array}$ & $\begin{array}{c}\text { CS } \\
{[\mathbf{M P a}]}\end{array}$ \\
\hline R2 & 890 & 0.195 & 22.4 & 1.55 \\
\hline R3 & 770 & 0.170 & 20.2 & 1.75 \\
\hline R4 & 910 & 0.205 & 19.8 & 2.85 \\
\hline R5 & 920 & 0.190 & 15.1 & 3.10 \\
\hline R6 & 760 & 0.175 & 15.7 & 3.5 \\
\hline
\end{tabular}

\section{Conclusion}

Bio-aggregate waste material such as hemp hurds is very attractive lignocellulosic filler/reinforcing element in bio-composite with inorganic matrix for novel environmentally friendly building materials. Such non-conventional construction materials - bio-aggregate-based composites with alternative binder $\mathrm{MgO}$-cement present sustainable materials with lower environmental impact as an alternative option for cost effective housing. Based on the presented results and their discussion, the following conclusions were formulated:

- Comparative study of bio-composites with MgO-cement showed an effect of treatment process of hemp hurds and nature of $A B$ constituents on the physical and mechanical properties during 
hardening. Chemical and physico-chemical treatment of $\mathrm{HH}$ affected favourably thermal conductivity and short-term water sorption behaviour of 28,60 and 90 days hardened bio-composites with MgOcement matrix compared to original $\mathrm{HH}$. The significant increase in compressive strength of biocomposites with ultrasound modified hemp hurds (UWTHH) due to changes in the morphology of the complex structure of the bio-aggregates during their physical modification procedure taking place on the fibrillary level.

- Modified MgO-cement formulation by replacement of the $A B$ components with reactive substances ( $\mathrm{MgO}$ calcined under optimal conditions and silica fume) without alkaline addition with incorporation of original $\mathrm{HH}$ into bio-based composites led to two times higher value of strength parameter compared to $\mathrm{RHH}$ composite after 28 days of hardening. This recipe seems to be suitable for preparation of bio-based composite.

\section{Acknowledgements}

This work was supported by the Slovak Scientific Grant Agency VEGA for the project VEGA $1 / 0222 / 19$.

\section{References}

[1] INGRAO, C. - LO GUIDICE, A. - BACENETTI, J. - TRICASE, C. - DOTELLI, G. - FIALA, M. SIRACUSA, V. - MBOHWA, C.: Energy and environmental assessment of industrial hemp for building applications: A review. Renewable and Sustainable Energy Reviews, Vol. 51, 2015, pp. $29-42$.

[2] TESLÍK, J. - FABIAN, R. - HRUBÁ, B. Determination of the airborne sound insulation of a straw bale partition wall. Civil and Environmental Engineering, Vol. 13, Iss. 1, 2017, pp. 20-29.

[3] MORGAN, J. Hemp Fibres 'Better Than Graphene'. BBC News: Science and Environment, 2014. Available at: http://www.bbc.co.uk/news/science-environment-28770876.

[4] AMZIANE, S. - COLLET, F.: Bio-aggregates based building materials. RILEM State-of-the-Art Reports, Springer, 2017, $262 \mathrm{p}$.

[5] CÉLINO, A. - FRÉOR, S. - JACQUEMIN, F. - CASARI, P. J.: Characterization and modeling of the moisture diffusion behavior of natural fibers. Applied Polymer Science, Vol. 130, 2013, pp. 297306.

[6] DOUDART DE LA GRÉE, G. C. H. - YU, Q. L. - BROUWERS, H. J. H.: Assessing the effect of $\mathrm{CaSO} 4$ content on the hydration kinetics, microstructure and mechanical properties of cement containing sugars. Construction and Building Materials, Vol. 143, 2017, pp. 48-60.

[7] CRINI, G. - LICHTFOUSE, E. - CHANET, G. - MORIN-CRINI, N.: Applications of hemp in textiles, paper industry, insulation and building materials, horticulture, animal nutrition, food and beverages, nutraceuticals, cosmetics and hygiene, medicine, agrochemistry, energy production and environment: a review. Environmental Chemistry Letters, Vol. 18, Iss. 5, 2020, pp. 1451-1476.

[8] PACHECO-TORGAL, F. - JALALI, S.: Cementitious building materials reinforced with vegetable fibres: A review. Construction and Building Materials, Vol. 25, Iss. 2, 2011, pp. 575-581.

[9] ARIZZI, A. - CULTRONE, G. - BRUMMER, M. - VILES, H.: A chemical, morphological and mineralogical study on the interaction between hemp hurds and aerial and natural hydraulic lime particles: Implications for mortar manufacturing. Construction and Building Materials, Vol. 75, 2015, pp. 375-384. DOI: 10.1016/j.conbuildmat.2014.11.026.

[10] DE BRUIJN, P. B. - JEPSSON, K. H. - SANDIN, K. - NILSSON, C.: Mechanical properties of lime-hemp concrete containing shives and fibres. Biosystem Engineering, Vol. 103, Iss. 4, 2009, pp. 474-479. DOI: 10.1016/j.biosystemeng.2009.02.005.

[11] GARTNER, E. M. - MACPHEE, D. E.: A physico-chemical basis for novel cementitious binders. Cement and Concrete Research, Vol. 41, Iss. 7, 2011, pp. 736-749.

[12] WALLING, S. A. - KINOSHITA, H. - BERNAL, S. A. - COLLIER, N. C. - PROVIS,J. L.: Structure and properties of binder gels formed in the system $\mathrm{Mg}(\mathrm{OH}) 2-\mathrm{SiO} 2-\mathrm{H} 2 \mathrm{O}$ for immobilisation of Magnox sludge. Dalton Transactions, Vol. 44, 2015, pp. 8126-8137.

[13] KIDALOVA, L. - STEVULOVA, N. - TERPAKOVA, E. - SICAKOVA, A.: Utilization of alternative materials in lightweight composites. Journal of Cleaner Production, Vol. 34, Iss. 1, 2012, pp. 116 119.

[14] CIGASOVA, J. - STEVULOVA, N. - JUNAK, J.: Influence of binder nature on properties of lightweight composites based on hemp hurds. International Journal of Modern Manufacturing Technologies, Vol. 5, Iss. 2, 2013, pp. 27-31. 
[15] ŠTEVULOVÁ, N. - ČIGÁŠOVÁ, J. - SCHWARZOVÁ, I. - SIČÁKOVÁ, A. - JUNÁK, J.: Sustainable bio-aggregate-based composites containing hemp hurds and alternative binder. Buildings, Vol. 8, Iss. 2, 2018, pp. 1-14.

[16] STEVULOVA, N. - CIGASOVA, J. - ESTOKOVA, A. - TERPAKOVA, E. - GEFFERT, A. - KACIK, F. - SINGOVSZKA, E. - HOLUB, M.: Properties characterization of chemically modified hemp hurds. Materials, Vol. 7, Iss. 12, 2014, pp. 8131-8150.

[17] STEVULOVA, N. - ESTOKOVA, A. - CIGASOVA, J. - SCHWARZOVA, I. - KACIK, F. GEFFERT, A.: Thermal degradation of natural and treated hemp hurds under air and nitrogen atmosphere. Journal of Thermal Analysis and Calorimetry, Vol. 128, Iss. 3, 2017, pp. 1649-1660.

[18] TERPAKOVA, E. - KIDALOVA, L. - ESTOKOVA, A. - CIGASOVA, J. - STEVULOVA, N.: Chemical modification of hemp shives and their characterization. Procedia Engineering, Vol. 42, 2012, pp. 1017-1028.

[19] STN EN 12390-7. Testing hardened concrete. Part 7: Density of hardened concrete. Slovak Office of Standards, Metrology and Testing: Bratislava, Slovakia, 2011.

[20] STN EN 12087/A1. Thermal insulating products for building applications. Determination of long term water absorption by immersion. Slovak Office of Standards, Metrology and Testing: Bratislava, Slovakia, 2013.

[21] STN EN 12390-3. Testing hardened concrete. Part 3: Compressive strength of test specimens. Slovak Office of Standards, Metrology and Testing: Bratislava, Slovakia, 2020.

[22] SCHWARZOVA, I. - STEVULOVA, N. - SINGOVSZKA, E. - TERPAKOVA, E. - JUNAK, J.: Effects of physical treatment of hemp fibers on fiber structure and biocomposite properties. Pollack Periodica, Vol. 10, Iss. 3, 2015, pp. 1117-124.

[23] DIQUÉLOU, Y. - GOURLAY, E. - ARNAUD, L. - KUREK, B.: Impact of hemp shiv on cement setting and hardening: Influence of the extracted components from the aggregates and study of the interfaces with the inorganic matrix. Cement and Concrete Composites, Vol. 55, 2015, pp. 112-121.

[24] STEVULOVA, N. - SCHWARZOVA, I. - ESTOKOVA, A. - HOLUB, M.: MgO-based cement as an inorganic binder for hemp hurds composites. Cheminé Technologija, Vol. 67, Iss. 1, 2016, pp. 24-29.

[25] ZHANG, T. - CHEESEMAN, C. R. - VANDEPERRE, L. J.: Development of low pH cement systems forming magnesium silicate hydrate (M-S-H). Cement and Concrete Research, Vol. 41, Iss. 4, 2011, pp. 439-442.

[26] TOLÊDO FILHO, R. D. - GHAVAMI, K. - ENGLAND, G.L. - SCRIVENER, K.: Development of vegetable fibre-mortar composites of improved durability. Cement and Concrete Composites, Vol. 25, Iss. 4, 2003, pp. 185-196. 